\title{
Reflexões sobre os estudos do processo de criação em diálogo com a história da crítica Genética
}

Cecília Almeida Salles ${ }^{1}$

ESTE ARTIGO TEM O OBJETIVO DE DESENVOLVER ALGUMAS REFLEXÓES SOBRE os estudos do processo de criação em diálogo com a história da Crítica Genética. Partirei da discussão de um filme e de um livro, anteriores ao surgimento do ITEM/CNRS e algumas cartas que, aparentemente, foram escritas depois de ter tido algum tipo de contato com a pesquisa genética.

Gostaria de me concentrar em três casos, que parecem bastante instigantes para pensarmos em suas reverberações na expansão do escopo de ação desses estudos, ou seja, na crítica de processos de criação. Trata-se do filme "Le Mystère Picasso", do cineasta Henri-Georges Clouzot de 1955; do livro de Rudolf Arnheim, The genesis of a painting: Picasso's Guernica (A gênese de um quadro: a Guernica de Picasso), publicado em 1962 pela Universidade da Califórnia (EUA); e das cartas de Villém Flusser, para o artista plástico Antônio Henrique Amaral, em 1974².

Outros casos semelhantes já foram objeto de muitos estudos desenvolvidos por pesquisadores de Crítica Genética. Refiro-me às discussões sobre Paul Valéry, um crítico genético avant la lettre e quatro textos de Freud, que muito contribuem para reflexões sobre arte, O delirio e os sonhos na Gradiva de W. Jensen (1907); O escritor e a fantasia (1908), Uma recordação de infância de Leonardo Da Vinci (1910) e O Moisés de Michelangelo (1914).

Quanto aos textos freudianos, acredito que podem ainda ser estudados de modo mais aprofundado, sob o ponto de vista do que a psicanálise oferece aos estudos do processo criação ${ }^{3}$.

\section{Algumas datas importantes para a crítica genética}

Como sabemos os estudos genéticos tiveram seu início na França, em 1968, quando, por iniciativa de Louis Hay e Almuth Grésillon, o Centre National de la Recherche Scientifique (CNRS) criou uma pequena equipe de pesquisadores, germanistas ou de origem alemã, encarregada de organizar os manuscritos do poeta alemão Heinrich Heine, doados, recentemente, à Biblioteca Nacional da França (BNF). Estes pesquisadores enfrentaram problemas metodológicos ao trabalhar com tais manuscritos. O primeiro momento dos estudos genéticos (1968-75), denominado por Almuth Grésillon (1991) “momento germânico-ascético", foi seguido pelo "momento associativo-expansivo" (1975-1985), quando se instaurou o diálogo entre o primeiro grupo de pesquisadores e outros, que começavam a se interessar pelo estudo dos manuscritos de Proust, Zola, Valéry e Flaubert: problemas comuns os uniam. É nesta fase, quando se dá a passagem de um projeto específico para uma problemática geral, que é criado um laboratório próprio, no CNRS: Institut des Textes et Manuscrits Modernes (ITEM), dedicado exclusivamente aos estudos do manuscrito literário.

\footnotetext{
${ }^{1}$ Pós-Doutorada em Cinema, Rádio e Televisão. É professora titular do Programa de Pós-Graduação em Comunicação e Semiótica da Pontifícia Universidade Católica de São Paulo. E-mail: cecília.salles@gmail.com

${ }^{2}$ Tomei conhecimento destas cartas a partir de uma pesquisa de minha orientanda de mestrado, Julia Meireles de Lima no Arquivo Vilém Flusser, São Paulo - www.arquivovilemflussersp.com.br

${ }^{3}$ A tese de doutorado de minha orientanda Paula Martinelli, em andamento, discutirá estes textos, estabelecendo relações com a expansão dos estudos de processo de criação.
} 
É importante lembrar que o termo, Crítica Genética, passa a ser usado de forma corrente somente a partir da publicação Essais de critique génétique: textes et manuscrits (Ensaios de crítica genética: textos e manuscritos), de Jean-Bellemin-Noel, em 1979.

A terceira fase na evolução das pesquisas, em Crítica Genética, segundo Grésillon, é o "momento justificativo-reflexivo", que se iniciou em 1975. Após toda fase conquistadora, como bem o sabemos, há a fase exploradora, que gera, naturalmente, expansão.

A partir de meados dos anos de 1990, os estudos genéticos vivem uma época de exploração e alargamento de horizontes. $\mathrm{O}$ tempo de reflexões sobre os princípios fundamentais e legitimidade da disciplina abriu espaço para a "ação transdisciplinar da Crítica Genética" (Almuth Grésillon), que se caracterizava, naquele momento, por maior número de escritores estudados e abordagens teóricas utilizadas e, assim, diferentes ângulos da criação literária eram discutidos.

A expansão se deu, também, geograficamente, quando, em meados dos anos 80, essa linha de pesquisa chegou ao Brasil. Em 1985, realiza-se, em São Paulo, o I Colóquio de Crítica Textual: o Manuscrito Moderno e as Edições, na Universidade de São Paulo. A Crítica Genética é, assim, introduzida no Brasil, por Philippe Willemart, que foi o responsável pela organização deste Colóquio e que, naquele momento, já vinha se debruçando sobre os manuscritos de Gustave Flaubert. Nesse mesmo colóquio, foi fundada a Associação de Pesquisadores do Manuscrito Literário (APML), hoje a APCG (Associação de Pesquisadores de Crítica Genética), que vem organizando, com periodicidade, encontros internacionais, e criou esta revista, Manuscrítica, em 1990, totalmente dedicada à divulgação dos estudos genéticos.

A expansão dos estudos dos registros de processo no Brasil tomou rumos diversos, explorando a interdisciplinaridade, também no campo dos objetos estudados e sofrendo alguns ajustes, de propósito, em seus diferentes contextos acadêmicos. Destaco aqui o interesse do grupo de pesquisa do Programa de Pós-Graduação em Comunicação e Semiótica (PUC/SP), pelo processo de criação, em sentido amplo, discutido mais adiante.

Importante destacar, nesta contextualização histórica da Crítica Genética, um fato que me parece relevante: o ITEM foi criado no conturbado e culturalmente fértil ano de 68, na França, no auge das abordagens estruturalistas. Retomarei essa questão, ao discutir as cartas de Flusser.

Com essas referências históricas em mente, volto ao recorte escolhido para as reflexões aqui propostas, também tratado em sua cronologia.

\section{Clouzot, Arnheim, Elusser}

Começo, portanto, pelo filme de Clouzot, "Le Mystère Picasso" (1956), que é uma filmagem do artista em ação, um interessante acompanhamento do trabalho de Picasso, porém artificial: é o processo como espetáculo. Um set de cinema transformado em ateliê, com luzes e equipe de filmagem, telas transparentes e tempo de produção das pinturas, determinado pelo tempo do cinema, às vezes sob a forma de um jogo entre o pintor e o cineasta. Há ainda a trilha sonora, que prepara o tema das futuras telas, numa construção dramática, reforçando o efeito dramático do espetáculo narrado.

É interessante destacar, porém, que pelo contrato, Picasso exigiu que as pinturas produzidas para esse documentário fossem destruídas, ao fim da filmagem.

Ao mesmo tempo, um conhecedor de outras obras deste pintor reconhece, nos quadros produzidos ao longo do documentário, traços e imagens recorrentes de seu projeto artístico. Não há dúvida de que o filme oferece um mergulho no universo imagético da criação de Picasso. 
Com todas essas ressalvas, é importante destacar que se trata de um acompanhamento do processo de Picasso. O filme traz à tona o interesse pelo processo do pintor, que também atraiu o pesquisador de artes visuais, Rudolf Arnheim.

É interessante observar que, mesmo sem o nome Crítica Genética, Arnheim, em sua publicação The Genesis of a Painting: Picassos's Guernica (A gênese de uma pintura: a Guernica de Picasso) (1964), faz um estudo aprofundado sobre o processo de criação de Picasso, a partir dos esboços de sua famosa obra, Guernica. Para falar da relevância dessa documentação, ele cita Picasso:

Pinturas nada mais são do que pesquisa e experimento [...] nunca faço uma pintura como uma obra de arte. Todas são pesquisa. Procuro por elas constantemente e há uma sequência lógica nessa busca. Por isso as numero. É um experimento no tempo. Eu as numero e dato. Talvez algum dia alguém seja grato ${ }^{4}$.

Arnheim, em sua defesa pela relevância do processo, diz que para Picasso, sua performance mais significativa não está em um trabalho único, mas na soma de todos eles; no processo de flutuação e transformação contínua presente pela sequência de esforços. Assim como anos mais tarde, Calvino, em seu livro Seis propostas para o próximo milênio (1990), afirma que a obra consiste em uma cadeia infinita de agregação de ideias, isto é, em uma série infinita de aproximações para atingi-la ${ }^{5}$.

"Toda pessoa criativa", continua Arnheim "sabe que um trabalho não é final, mas só um mero passo para outras realizações; no entanto, seu olho é treinado sobre esse objetivo final a ser alcançado, não sobre a jornada como um propósito em si”,

Neste contexto, Arnheim escolhe seu objeto de estudo: as sobras, restos (leftovers) de Picasso no processo de criação da Guernica: desenhos e pinturas mais muitas fotografias tiradas no estúdio de Picasso, de várias fases da própria tela ${ }^{7}$.

É interessante observar que tanto a pesquisa batizada pelos pesquisadores franceses, alguns anos depois, como o título do livro de Arnheim têm o estudo da "gênese" como tema, com o objetivo de compreender como poemas e telas são criados. Não se pode negar que esse termo tem uma forte carga de busca pela origem, no sentido bíblico. Com o desenvolvimento desses estudos, mais nos confrontamos com a ausência desses tão buscados pontos iniciais, assim como finais ${ }^{8}$.

Importante destacar que Arnheim ${ }^{9}$ oferece a seu leitor algumas interessantes conclusões sobre a criação de Picasso, a partir de algumas sobras ou documentos de seu processo. Observa que a combinação de crescimento e execução, no processo criativo, leva a um procedimento que não pode ser descrito como a elaboração sucessiva de fragmentos ou partes, mas sim como uma elaboração ao longo da qual cada parte atua sobre a outra. Uma interação de interferências, modificações, restrições e compensações conduz, gradualmente, à complexidade do todo da composição.

${ }^{4}$ ArnheIm, R. The genesis of a painting. Picasso's Guernica. Berkeley, Los Angeles, Lodon: University of California Press, 2006, p.13.

${ }^{5}$ CALVINO, I. Seis propostas para o próximo milênio. São Paulo, Companhia das Letras, 1990

${ }^{6}$ ARnheIM, R. The genesis of a painting. Picasso's Guernica. Berkeley, Los Angeles, Lodon: University of California Press, 2006, p.14.

${ }^{7}$ Ibidem., p.13.

${ }^{8}$ Ver SALLES, C.A. Gesto Inacabado: processo de criação artística. (2011) 5a ed. revista e ampliada. São Paulo: Intermeios, 2011.

9 ARnheIM, R. The genesis of a painting. Picasso's Guernica. Berkeley, Los Angeles, Lodon: University of California Press, 2006, p.149. 
Conhecemos também, a partir de seu estudo, muitos detalhes sobre o nascimento, movimentos e relações das personagens dessa obra do artista. A coreografia das figuras é responsável por alguns aspectos da dramaturgia desse processo.

É sempre interessante lembrar que o histórico destes estudos tem estas datas bem definidas, se levarmos em conta a natureza oficial do uso do termo crítica genética, no âmbito acadêmico. No entanto, muitos outros pensadores fizeram estudos sobre o processo criador, a partir de "manuscritos" de artistas. Vale lembrar que Ítalo Calvino (1990) também fez crítica genética, sem o saber, quando vê os manuscritos de Leonardo da Vinci abrindo uma fresta para o funcionamento de sua imaginação.

O livro de Arnheim foi publicado no contexto das discussões norte-americanas, sobre criatividade, dos anos de 1960, em diálogo com abordagens da psicologia e psicanálise, como fica claro em seu capítulo inicial. É interessante observar que ele vê o potencial de pesquisa e conhecimento, sobre criatividade, guardado pelos documentos do processo, como índices da criatividade em ação, ou do pensamento em processo. Ele abre seu livro com a afirmação de que a mente humana não é facilmente acessível, e vê o estudo dos esboços como uma forma de se aproximar da "criatividade da mente humana", com o foco nas artes visuais, seu campo de pesquisa.

Nesta tentativa de aproximação do modo de funcionamento da mente humana, ele coloca em debate a questão da artificialidade da observação direta. Diz que a mente tende a encolher quando está sendo observada. Afirma que se alguém desejar espionar a si mesmo, este alguém entra na "situação crítica" descrita por Kant, em sua Antropologia quando os poderes físicos estão em ação, não se observa; e quando alguém se observa, esses poderes param.

Sem mencionar o filme de Clouzot, Arnheim afirma que "ver um artista trabalhando - ver um filme de Picasso ou Matisse pintando um quadro - é revelador; mas aqui novamente, a atividade privada de dar à luz a uma obra de arte sofre com a presença de testemunhas ${ }^{10 ”, ~ e m ~ c o n s o n a ̂ n c i a ~ c o m ~ o s ~ c o m e n t a ́ r i o s ~ q u e ~ f i z ~ s o b r e ~ o ~}$ filme anteriormente. Arnheim continua:

É por esse motivo que as sobras materiais do processo criativo - os rascunhos dos poetas, as versões iniciais, os manuscritos com suas correções, os cadernos dos compositores, os desenhos preparatórios dos artistas, os vários estados de gravuras, as fotografias de um trabalho em processo, as análises de raio-x de pinturas - foram apreendidas como os dados mais tangíveis e confiáveis ${ }^{11}$.

E faz uma ressalva: "É verdade que esses documentos íntimos de tentativa e erro podem ser influenciados pela conscientização do artista de que alguém pode coletá-los e lê-los posteriormente" ${ }^{\text {"12 }}$.

Associo esta ressalva à anotação que encontrei nos diários de Ignácio de Loyola Brandão, quando estava escrevendo Não Verás País Nenhum (1981):

Gostaria de conhecer a sensação de uma pessoa que penetra dentro deste torrencial de apontamentos, informações, dados, frases desconexas. Para mim, o terreno é familiar. Pantanal, mas sei o caminho seguro através dele. Que ideia um outro fará? Terá interesse? Se perde? Ou de repente se conduz bem dentro deles? ${ }^{13}$.

\footnotetext{
${ }^{10}$ ArnheIM, R. The genesis of a painting. Picasso's Guernica. Berkeley, Los Angeles, Lodon: University of California Press, 2006, p. 13.

${ }^{11}$ Ibidem.

${ }^{12}$ Ibidem.

${ }^{13}$ Arquivo do escritor.
} 
Essa indagação de Arnheim encontra, a meu ver, possíveis respostas, quando ouvimos os artistas falando da relevância desses documentos ou dos momentos privados dos processos de criação. Como a constatação do coreógrafo Murray Louis de que o público não tem ideia quanta esplêndida arte se perde por não assistir aos ensaios ${ }^{14}$.

Voltamos assim, à artificialidade da observação na filmagem, que reaparece nas cartas de Flusser, como uma metodologia para um maior conhecimento sobre os gestos dos artistas. Ele publica o texto Gesto de pintar, em 1975. Este mesmo texto aparece em uma publicação mais recente, intitulada Gestos (2014), composta por sete ensaios e uma introdução intitulada Esboços para uma introdução a uma Teoria Geral dos Gestos.

Sua conversa com Antônio Henrique Amaral torna-se, em determinados momentos, ruidosa, trazendo questões relevantes para o debate aqui proposto. Pelas cartas sabemos que Flusser fez um artigo sobre uma obra do artista e o comenta, em meio à sua busca por uma fenomenologia do corpo.

$\mathrm{Na}$ carta de 30/6/74, diz que poderia procurar ver o que o artista "revela de seu íntimo com relação à banana, o que você procura esconder, e isto tudo por intermédio de seu 'estar-aqui-em-carne-e-osso" "15. Diz que no artigo não fez isso. "Para poder fazê-lo, deveria ter observado você em ato, como fiz com Mira, Vega ou Flexor (Flexor fez retrato de mim e eu escrevia crítica enquanto ele pintava)".

Não temos acesso à resposta do artista, mas podemos imaginar que ele faz uma crítica à artificialidade do acompanhamento, pois na carta 13 de julho, Flusser comenta:

Gesto: Você tem muita razão na afirmativa que a observação modifica o gesto (tanto a observação por outro, quanto a observação do próprio gesto).[...] No entanto, considere: toda obra deste ponto de vista, permite duas leituras: (a) a "formal", na qual a obra mesma é o fenômeno, e nada mais interessa, e (b) a "genética" na qual a obra é como que ponta de lança invisível ou ponta de iceberg.

É importante destacar duas questões sobre o uso do termo genética por Flusser, em 1974, sem que saibamos se ele teve algum tipo de contato com os pesquisadores franceses; e a referência à leitura formal associada às abordagens estruturalistas, já mencionadas na contextualização do surgimento do ITEM. Flussser continua a carta, defendendo a necessidade das duas abordagens:

Para captar a obra, as duas leituras devem ir de mãos dadas. Toda a leitura (b) pressupõe a análise do contexto da obra, a análise das condições históricas e outras da obra, e a análise da interioridade do artista. Se o artista está fora do alcance, (por exemplo morto), devo reconstruir seu gesto a partir da obra. Mas se é acessível, posso recorrer (embora problematicamente), à observação da sua práxis, já talvez respondendo ao incômodo sentido pelo artista.

Flusser diz que a vantagem da leitura "genética" é que "na reconstrução extrapolo, mas na observação posso permitir ao fenômeno mesmo, (ao gesto do artista), que me fale. Neste caso devo, obviamente, tomar em consideração a interferência que minha observação exerce no gesto. Você concorda?”. Não sabemos se Antônio Henrique Amaral concordou.

\footnotetext{
${ }^{14}$ LouIs, M. Dentro da dança. Rio de Janeiro, Nova Fronteira, 1992.

${ }^{15}$ Os trechos das correspondências discutidas aqui estão disponíveis no Arquivo Vilém Flusser, São Paulo. Disponível em: http://www.arquivovilemflussersp.com.br/vilemflusser/.
} 
Importante ressaltar que, em meio a essa estranha rede de não citações ou qualquer tipo de referências, Flusser, em 1974, faz a escolha pela metodologia da observação do artista em ação, que não está presente no começo dos estudos genéticos franceses, surgidos no fim dos anos de 1960; e Arnheim, por sua vez, recorreu à metodologia da análise dos documentos antes da crítica genética "oficial", em oposição à metodologia do acompanhamento dos processos, como em filmagens de artistas trabalhando, concretizado no filme de Clouzot.

Trago para essas reflexões o livro Um retrato de Giacometti, do crítico de arte James Lord, publicado na França em 1965. Lord, assim como Flusser e Flexor, foi modelo do artista e narra o que ele viveu no ateliê, "recriando o clima das conversas que tinham, fazendo observação sobre a maneira como Giacometti pintava e descrevendo as transformações pelas quais o quadro ia passando" ${ }^{\text {, }}$, como relata C. Euvaldo, na apresentação da publicação brasileira "esta forma de relato, acompanhando o artista no tempo real de execução de uma obra, é um documento precioso" ${ }^{\prime 1}$.

Destaco algumas questões importantes para nossa discussão: o crítico/modelo e o artista eram muito amigos, podendo dizer que ele fazia parte das redes de criação de Giacometti; todo fim do dia, ele fotografava a tela em processo; e, ao longo do livro, ele menciona os cuidados para fazer anotações ao término das sessões, sem que Giacometti se sentisse invadido.

\section{Recorrências no debate}

Chegamos ao fim desta parte da discussão, com algumas observações importantes para a continuidade dessas reflexões no âmbito da expansão dos estudos sobre processo de criação.

Observamos que a constatação do potencial dos documentos ou sobras dos processos para a compreensão dos processos de criação foi recorrente, assim como o debate sobre a metodologia de acesso a esses percursos. Destaco ainda a constante delimitação a estudos de caso, ou seja, com o propósito de compreender a singularidade de determinado artista. Talvez a única exceção seja a menção de Flusser a uma fenomenologia do corpo.

Como mencionei anteriormente, a partir dos anos de 1990, os estudos genéticos no Brasil estão vivendo uma época de expansão em uma grande diversidade de direções, sem a dependência das nomeações de fases e rumos dados pelos franceses.

Meu olhar é moldado pela experiência na PUC/SP, com o grupo de pesquisa em processos de criação, que coordeno desde 1993. De modo bastante sucinto, posso dizer que passamos pela ampliação dos objetos de estudo da literatura para a arte em geral, além do jornalismo, publicidade, design e ciência. Passa-se a pensar, assim, no agente criativo em sentido amplo.

Quanto ao estudo das singularidades, a grande diversidade de estudos de caso gerou imersões nas especificidades do artista estudado, e levou-me a observar que há questões recorrentes em muitos processos. No mergulho cego no específico, perde-se a noção daquilo que é geral. Esta inquietação teórica e metodológica levou à construção de uma teoria geral ao longo do tempo, que discute a criação como rede em construção.

Como já mencionei em outros textos, sob esta perspectiva, tínhamos, no início da história do desenvolvimento da Crítica Genética, estudos propiciando conhecimento sobre as especificidades de alguns processos. A metodologia do estudo de documentos era, naquele momento, mais geral do que os resultados singulares, aos quais as pesquisas chegavam. À medida que uma possível teoria da criação é configurada, há uma

\footnotetext{
${ }^{16}$ Euvaldo, C. Giacometti: observando e sendo observado. In: LORD, James. Um retrato de Giacometti. São Paulo, Iluminuras, 1998, p. 9-10.

${ }^{17}$ Ibidem.
} 
inversão de perspectiva: a teorização passa a ser mais geral do que a metodologia restrita aos estudos de caso, que passa a estar a serviço de algo mais amplo, que é a teorização sobre o processo criador.

Esta teorização sustenta a crítica de processos de criação. É essa expansão do escopo de ação dos estudos de processo que conduz às reflexões que se seguem. Não podemos deixar de mencionar a relevância da relação com a experimentação contemporânea, na quebra de limites metodológicos e teóricos. Como pensar, por exemplo, a ida dos documentos ou arquivos de criação para o espaço expositivo ou cênico?

Como a questão metodológica do acompanhamento do processo veio à tona, pelos casos aqui discutidos, proponho uma reflexão mais aprofundada sobre suas diferentes possibilidades, em pesquisas recentes. Metodologia essa, que vem passando por transformações, enfrentando inclusive o pedido de artistas para que seus processos sejam filmados.

\section{Acompanhamento de processos}

Essa discussão parte da minha experiência e a de meus orientandos, nos acompanhamentos de processo e o pedido de um artigo para uma revista de pesquisadores das artes cênicas, sobre tais acompanhamentos.

Não há dúvida de que no caso dos processos em grupo, a presença de alguém, ao longo do percurso, é sempre facilitada e menos artificial do que no caso dos processos ditos individuais ${ }^{18}$. O grupo se amplia, mas é sempre mais um olhar. Não se pode falar de observador neutro. Há sempre interação entre os membros do grupo e o observador. Acredito que no contexto do pensamento da complexidade, fugindo da crença na objetividade das ciências clássicas, partimos da "inevitável" interação de subjetividades. Se tomarmos o conceito de criação como rede, o observador será sempre parte da rede da criação que o grupo está desenvolvendo.

Neste contexto, é interessante voltar à publicação de James Lord, na qual se pode observar que dá materialidade a uma passagem do processo do artista visual em frente à sua tela (nos casos aqui discutidos), e um processo em grupo, em que o modelo faz parte desses processos.

Para iniciar essas reflexões de natureza mais geral, proponho pensarmos no propósito e no contexto dos acompanhamentos. Qual o objetivo de assistir a ensaios, debates, workshops, palestras etc. e qual a relação do observador com o grupo?

Quanto aos propósitos, seria importante levantar algumas possibilidades desse acompanhamento, que levam a questões gerais metodológicas, mas também a algumas de suas especificidades.

Sob o ponto de vista do grau de envolvimento do observador, já se colocam algumas perguntas, que vão gerar, por sua vez, modos diferentes de acompanhamento. Trata-se de um pesquisador acadêmico, um crítico de processo, um crítico das artes cênicas, um pesquisador das artes cênicas, um artista, um artista/pesquisador, de fora do grupo, que está fazendo um mestrado ou doutorado, ou pesquisador, parte do grupo, vivenciando o próprio processo? Trata-se de um pesquisador externo ao grupo, ou alguém convidado para acompanhar o processo? Cada contexto gera seus propósitos e perguntas específicos.

${ }^{18}$ Colapietro (2014), ao discutir o sujeito sob o ponto de vista da semiótica, diz que o artista, em nosso caso, não é uma esfera privada, mas um agente comunicativo. É distinguível, porém não separável de outros, pois sua identidade é constituída pelas relações com outros; não é só um possível membro de uma comunidade, mas a pessoa, como sujeito, tem a própria forma de uma comunidade, ressalta o que parece de extrema relevância para se colocar em crise a oposição entre processos em grupo e processos individuais. Ver mais em SALLES, C.A. Processos de criação em grupo: diálogos. São Paulo: Estação das Letras e Cores Ed, 2017. 
Estas são algumas possibilidades, sabendo que não se pode esgotar esta listagem. $\mathrm{O}$ importante a destacar é que esses propósitos diferentes geram modos de acompanhamento diversos, assim como "produtos", só para citar alguns exemplos: textos críticos, TCCs, mestrados, doutorados, artigos etc. Os registros audiovisuais de cineastas, convidados para acompanhar o grupo, que podem gerar documentários ou uso pelo grupo para retomar práticas esquecidas, em meio a processos colaborativos, workshops e improvisos, por exemplo.

Outras questões que se colocam relativas à metodologia do acompanhamento: tempo e modos de registrar as observações. O tempo está relacionado a muitas variáveis, tais como as possibilidades e propósitos do pesquisador, a abertura do grupo etc.

Quanto ao registro, minha experiência leva-me a falar sobre a preocupação de não ser invasivo, entender que tipo de interação o grupo espera, busca de linguagem comum e cuidados com a postura crítica. Estas observações podem gerar, por exemplo, anotações verbais ou audiovisuais. O que observar?

Os diferentes propósitos do observador geram perguntas diferentes, como já mencionei. Para o crítico de processo, por exemplo, a pergunta que move o pesquisador é "o que este acompanhamento oferece sobre o processo de criação do grupo?”. O crítico fica, assim, exposto ao que aquele processo vai oferecendo, sem predeterminação do que vai encontrar, aberto ao acaso da pesquisa, com as marcas inevitáveis do seu olhar e de seus interesses.

Voltando aos diferentes graus de envolvimento daquele que acompanha o processo, há diferentes formas de interação com o grupo. Só para dar um exemplo, Evaldo Mocarzel foi convidado para fazer o registro audiovisual do projeto Kastelo, uma adaptação de O Castelo de Franz Kafka, do Teatro da Vertigem. O grupo enfrentou alguns embates, tão comuns em tais processos. Neste caso, o cineasta passa a assinar a dramaturgia, juntamente com Sérgio Pires.

Esta metodologia do acompanhamento enfrenta também alguns questionamentos relativos à fundamentação teórica. Coloca-se aqui a pergunta: como a crítica de processos de criação pode auxiliar na leitura das observações dos acompanhamentos, produzindo conhecimento sobre criação?

O primeiro aspecto a ser destacado, em um contexto de reflexões ainda embrionárias, é que se trata de uma abordagem crítica, com as mesmas inquietações de quem se propõe a acompanhar o processo. Essas buscas em comum podem trazer à tona a importância das anotações e dos diários de atores, diretores (só para citar alguns exemplos) dos percursos acompanhados, cuja leitura pode ampliar o conhecimento sobre a criação daquele grupo. E os instrumentos de natureza geral dos processos, oferecidos por essa abordagem crítica, podem gerar reflexões sobre as especificidades dos processos acompanhados.

\section{Referências bibliográficas}

ARNHEIM, Rudolf. The genesis of a painting. Picasso's Guernica. Berkeley, Los Angeles, Lodon: University of California Press, 2006.

CALVINO, Italo. Seis propostas para o próximo milênio. São Paulo, Companhia das Letras, 1990.

Clouzot, Henri. Le mystère Picasso, 1956

COLAPIETRO, Vincent. Peirce e a abordagem do self: uma perspective semiótica sobre a subjetividade humana. São Paulo: Intermeios, 2014.

FREUD, Sigmund. O delírio e os sonhos na Gradiva de W. Jensen (1907). In: Obras Completas, Vol VIII, 1906-1909: O delírio e os sonhos na Gradiva e outros textos. Trad. Paulo César de Souza. São Paulo: Companhia das Letras, 2015.

O escritor e a fantasia (1908). In: Obras Completas, Vol VIII, 1906-1909: O delírio e os sonhos na Gradiva e outros textos. Trad. Paulo César de Souza. São Paulo: Companhia das Letras, 2015. 
Uma recordação de infância de Leonardo Da Vinci (1910). In: Obras Completas, Vol IX, 1909-1910: Observações sobre um caso de neurose obsessiva "O Homem dos Ratos", uma recordação de infância de Leonardo Da Vinci e outros textos. Trad. Paulo César de Souza. São Paulo: Companhia das Letras, 2013.

O Moisés de Michelangelo (1914). In: Obras Completas, Vol XI, 1912-1914: Totem e tabu, contribuição à história do movimento psicanalítico e outros textos. Trad. Paulo César de Souza. São Paulo: Companhia das Letras, 2012.

FLuSSER, Vilém. Gestos. São Paulo: Annablume, 2014.

EuvALDO, Célia. Giacometti: observando e sendo observado. In: LORD, James. Um retrato de Giacometti. São Paulo, Iluminuras, 1998.

LouIs, Murray. Dentro da dança. Rio de Janeiro, Nova Fronteira, 1992.

SALLES, Cecilia A. Gesto Inacabado: processo de criação artística. $5^{\text {a }}$ ed. revista e ampliada. São Paulo: Intermeios, 2011.

Processos de criação em grupo: diálogos. São Paulo, Estação das Letas e Cores, 2017. 